\title{
PHYSICAL SECTION
}

\author{
Slated Meeting, held December 26, r900
}

RECEN'T ADVANCES IN THE PHYSICS OF WATER.

GEORGE FiTOWLRS STRADLING, PH.D.

Member of the Institute.

For a long time it has been known that water, the most common of all liquids, has physical properties which vary widely from those of most other liquids. The large quantity of heat required to melt a gram of ice, the still larger quantity required to convert a gram of water into vapor at the same temperature and the existence of a temperature of maximum density between the melting and the freezing points, mark water as departing from the usual rules of liquid comportment. Already the list of the anomalies presented by water is long and yet it is no uncommon occurrence to have it increased. For instance Hauser in the July number of Drude's Annalen for $190 \mathrm{r}$ shows that at $32^{\circ} \mathrm{C}$., the viscosity of water is not changed by a pressure of 400 atmospheres, while at other temperatures it is changed.

Within the last decade serious attempts have been made to furnish an explanation of the irregularities of water. The idea that water molecules are not $\mathrm{H}_{2} \mathrm{O}$ simply but are aggregates of this group is advanced by Raoult * as a result of his experiments upon the molecular lowering of the freezing point of solutions, and probably expressions of this view could be found long before. When in I89 I Roentgen attacked the problem he used this suggestion and succeeded in furnishing a qualitative explanation. $\dagger$

He regards water as composed of molecules of two kinds, which he designates ice molecules and molecules of the second kind. Ordinary water is considered to be a

\footnotetext{
* Raoult, Ann. chim et phys., Series 6, Vol. II, p. 66, 1884.

$\dagger$ Roentgen, Wied. Ann., XLV, p. 9r. "Ueber die Constitution des fliissigen Wassers."

VOL. CLII. NO. glo. 
saturated solution of ice molecules in a mass of molecules of the second kind. By the addition of heat ice molecules are converted into those of the second kind. This is accompanied by a diminution of volume, just as when ice melts.

The maximum density of water.-At $4^{\circ} \mathrm{C}$. water is at its maximum density. The addition of heat to a mixture of the two kinds of molecules will cause

(I) A diminution of volume due to the change of ice molecules into molecules of the second kind.

(2) An increase of volume due to the expansion of the mass of molecules of the second kind.

The observed change in the volume of water is the difference of these two effects. When heat is applied to water at $0^{\circ}$ a relatively large number of ice molecules are changed into the other kind and the diminution of volume amounts to more than the increase. As the temperature rises the number of ice molecules diminishes, hence fewer are changed into the second kind, and the difference be tween the diminution and increase grows less. At $4^{\circ}$ the two effects just balance each other, while above this temperature the increase of volume is the greater.

Roentgen gives this explanation but does not claim to be the originator of it. Indeed H. M. Vernon* in the same year gave practically the same explanation.

Pressure-Volume-Temperature Relations of Water.-As the temperature of simple liquids rises, their compressibility increases, but the compressibility of water grows less with rising temperature and, according to the results of S. Pagliani and $\mathrm{G}$. Vicentini, $\uparrow$ reaches a minimum value at $63^{\circ} \mathrm{C}$.

To explain this Roentgen further assumes that an in. crease of pressure upon a mass of water kept at constant temperature results in the change of some of the ice molecules into molecules of the second kind, and that the num-

*H. M. Vernon, Phil. Mag., Series 5, Vol. XXXI, p. 387 , 1891. "On the Maximum Density of Water."

†S. Pagliani und G. Vicentini. Beiblätter, VIII, p. 794. "Veber die Compressibilität der Fliissigkeiten und insbesondere des Wassers." 
ber so changing is greater as the total number of ice molecules present is greater. This transformation causes a diminution of volume which is greater for a given increase of pressure at low temperatures, because then the water is richer in ice molecules. When, therefore; pressure is exerted upon a mass of water, the resulting change of volume is the sum of

(I) A decrease of volume due to the transforming of ice molecules into those of the second kind, and

(2) A decrease due to the compression of the mass of molecules of the second kind.

The first of these decreases will grow smaller as the temperature rises, because with rising temperature the number of ice molecules becomes smaller. On the other hand the second will probably become greater as the temperature goes up. At least simple liquids act thus. From the opposite effects produced upon the two decrements by a rise of temperature it is seen that their sum, which is the actually observed compressibility of water, might at some temperature have a minimum value.

The effect of pressure upon the coefficient of thermal expansion of ether, carbon disulphide and alcohol is to lower it; but for water it has been found that the mean coefficient up to $50^{\circ}$ at least is increased, even when the pressures amount to $2500-3000$ atmospheres. To find an explanation for this anomalous effect, consider how an increase of pressure will act on both of the volume changes mentioned under the heading "The maximum density of water." The first, the diminution of volume, will be made less by an increase of pressure, because thereby the ice molecules are converted into the other kind, so that there remains fewer of them to be changed by heat. Roentgen had no data by which to determine how pressure would affect the second, the increase of the volume of the mass of molecules of the second kind. $\mathrm{He}$ suggests that perhaps there would be but little effect upon the coefficient of expansion. Let us now compare the thermal expansion of a mass of water under a pressure of one atmosphere with the expansion under a higher pressure, the rise of temperature 
being, for example, from $5^{\circ}$ to $10^{\circ} \mathrm{C}$. in both cases. The observed expansion under both pressures is the expansion of the aggregate of molecules of the second kind minus the decrease in volume due to the change by heat of some ice molecules into the others. Under the higher pressure the minuend is larger because there are more molecules of the second kind in the water, and the subtrahend is Tess because the number of ice molecules is smaller. The remainder, the observed thermal expansion, is therefore larger for the higher than for the lower pressure.

Amagat finds that at high pressures water comports itself as an ordinary liquid. This finds its explanation in the disappearance of ice molecules. His results likewise show that the effect of pressure upon the coefficient of thermal expansion is most marked when the temperature and the pressure are low. This is understood when it is recalled that the number of ice molecules is greater at $10 \mathrm{w}$ pressure and at low temperature.

Lowering of the temperature of maximum density by pressure.The temperature of maximum density moves downward from $4^{\circ} \mathrm{C}$. as the pressure upon the water is made greater.

According to the view already advanced, at $4^{\circ} \mathrm{C}$. and under atmospheric pressure the effect upon the volume of a mass of water caused by a small increase of temperature is zero, because there the two opposite volume changes just balance each other. An increase of pressure lessens the number of ice molecules and consequently gives to the expansion of the mass of molecules of the second kind the preponderance. Under this increased pressure, then, the balancing of the two effects no longer occurs at $4^{\circ}$, but at some lower temperature, where the water is richer in ice molecules.

By pressure water can be cooled below $0^{\circ} \mathrm{C}$. without freezing, because the pressure prevents the formation of ice molecules.

Viscosity of water.-Water under pressures of severa1 hundred atmospheres is less viscous than at normal pressure, provided the temperature does not exceed $32^{\circ} \mathrm{C}$. Other liquids which have been investigated grow more viscous with an increase of pressure. 
The viscosity of water is generally made greater by dissolving other substances in it, and the larger the quantity of the solute the greater in general is the viscosity. Its viscosity would accordingly be expected to increase with the proportion of ice molecules. An increase of pressure by reducing their number would reduce at the same time the viscosity. An increase of temperature lowers the viscosity for the same reason, and very likely also by decreasing the viscosity of the mass of molecules of the second kind.

From the investigations of $\mathrm{R}$. Cohen* it appears that the decrease of viscosity produced by a given increment of pressure is greater the lower the temperature. For instance, at $10^{\circ} \mathrm{C}$. the effect of an increase of pressure of 600 atmos. pheres is about six times as great as at $23^{\circ} \mathrm{C}$. This is to be attributed to the greater effect at $10^{\circ}$ of the pressure in re. ducing the number of ice molecules. Moreover, when the temperature is constant, he finds that a given increase of pressure produces a greater effect upon the viscosity when the pressure already exerted is small than when it is larger. As an illustration, when the temperature is $15^{\circ}$ an increase of pressure from 100 to 300 atmospheres produces a larger decrease in the viscosity than an increase from 300, to 600 atmospheres. The reason of this is to be found in the larger proportion of ice molecules present at low pressures and the consequent greater reduction in their number produced by the added pressure.

These results obtained by Cohen are of especial interest since they form the fulfilment of a prediction made by Roentgen "that the viscosity of water at high pressures will be less reduced by a given increase of pressure than at low pressures" and "that the effect referred to will for equal pressures be found to be the larger the lower the temperature of the water is."

Following the road marked out by Roentgen, a number of investigators have succeeded in finding the explanation

* R. Cohen. Wied. Ann., XLV, p. 666, 189 I. "Einfluss des Druckes auf die Viscosität von Flïssigkeiten." 
of some of the irregularities of water which he did not discuss. Hugo Witt * of Stockholm has applied the theory of ice molecules to several phenomena of aqueous solutions.

From the equation of equilibrium between the two kinds of water molecules in an aqueous solution, he infers that the presence of a solute has the effect of causing some of the ice molecules to change into those of the second kind. This at once explains why the volume of an aqueous solution is generally less than the sum of the volumes of the water and of the dissolved substance. The contraction is the result of the change of molecules of greater specific volume in to those of less.

We have seen that an increase of pressure lowers the temperature of maximum density of water. Now both pressure and the presence of a substance dissolved in water have the effect of reducing the number of ice molecules, and hence it is seen why the temperature of maximum density of an aqueous solution is below $4^{\circ} \mathrm{C}$.

Witt explains the high specific heat of water as due to the heat required to change the ice molecules into those of the second kind. Aqueous solutions nearly always have a lower specific heat than water. Even after making allowance for the solute, whose specific heat is of course less than that of water, it is found that the water in the solution seems to have a less specific heat than before the substance was dissolved in it. Witt attributes this to the solution's having fewer ice molecules than water, so that a rise of temperature of $\mathbf{I}^{\circ}$ will be followed by the transformation of fewer ice molecules and will therefore require a smaller quantity of heat. He finds in the heat requisite to change the ice molecules into the other kind a reason why the solution of substances in water is ustually accompanied by a lowering of temperature.

When a solid is dissolved in a liquid there is a decrease in the vapor tension of the liquid. Raoult has shown how

*Hugo Witt, Öfversigt af Kongl. Vetenskaps-Akademiens Förhaudlingar, I900, No. I, p. 63. "Ueber die Constitution des Wassers." 
to calculate this decrease. Now, when water is the solvent, Witt found that, even after allowing for the dissociating power of water, the observed lowering of the vapor tension is more than that calculated by Raoult's formula. $\mathrm{He}$ gives this explanation. 'There is reason to believe that the vapor tension of the ice molecules is greater than that of the others. The observed vapor tension of water probably lies between the two values. When a salt is dissolved in water, by its presence it occasions a lowering of the vapor tension; but in addition to this it causes some ice molecules to change into the second kind and thus the vapor tension is still further lowered. This last effect is not included in the formula of Raoult.

J. J. van Laar, of Utrecht, ${ }^{*}$ in a mathematical paper reaches the conclusion that water is made up of $\left(\mathrm{H}_{2} \mathrm{O}\right)_{2}$ groups which dissociate with rising temperature. He explains the occurrence of a temperature of maximum density for water very much as Roentgen does. The contraction of volume resulting from the mixture of alcohol and water he accounts for thus: Both have complex molecular groups formed by association of the molectles represented by the respective chemical formulas, and in both cases change from the complex to the simple form is attended by a shrinking of volume. When the two liquids are mixed both lose in complex molecules and gain in simple ones. Hence the volume decreases. He calculates that the change of $18 \mathrm{~g} . \mathrm{H}_{2} \mathrm{O}$ into $\left(\mathrm{H}_{2} \mathrm{O}\right)_{2}$ causes a lessening of the volume by $8.4 \mathrm{~cm}^{3}$.

In the experiments by Cohen referred to above it is shown that aqueous solutions of $\mathrm{NaCl}$, which are not concentrated, suffer no change in viscosity by the application of a pressure of 600 atmospheres, at a certain temperature for each strength of solution. Below that temperature the viscosity is lessened; above it is increased. Now the behavior of water is the samef except that the temperature

* J. J. van Laar, Zeitschrift für physikalische Chemie, XXXI, p. I. "Ueber die theilweise Association der Flüssigkeiten."

†L. Hauser, Drude's Annalen., V, p. 597, Igor. "Ueber den Einfluss des Druckes auf die Viscosität des Wassers." 
of no effect is higher. We can find an explanation of this downward displacement of the temperature by recalling that, in accordance with the ideas of Witt and van Laar, the number of ice molecules in water at a certain temperature is the same as the number in a solution of salt in water at a lower temperature.

Within the past year a paper by Sutherland* has appeared in which a vigorous and successful attempt is made to furnish a quantitative explanation of the anomalies of water. The author aims to show that steam consists of $\mathrm{H}_{2}$ $\mathrm{O}$, ice of $\left(\mathrm{H}_{2} \mathrm{O}\right)_{3}$, and water of a mixture of $\left(\mathrm{H}_{2} \mathrm{O}\right)_{3}$ and of $\left(\mathrm{H}_{2}\right.$ $\mathrm{O})_{22}$. He calls $\mathrm{H}_{2} \mathrm{O}$ hydrol, $\left(\mathrm{H}_{2} \mathrm{O}\right)_{2,}$ dihydrol, and $\left(\mathrm{H}_{2} \mathrm{O}\right)_{2}$, trihydrol. According to this nomenclature Roentgen's ice molecules are trihydrol and his molecules of the second kind dihydrol. The chief results of the paper in the calculation of the physical constants of dihydrol and of trihydrol are given in the following table:

\begin{tabular}{|c|c|c|c|c|c|c|c|}
\hline \multirow{2}{*}{ Dihydrol. . } & $\begin{array}{l}\text { Density, } \rho_{O} \text {, } \\
\text { at } 0^{\circ} \mathrm{C} \text {. }\end{array}$ & \multicolumn{2}{|c|}{$\begin{array}{l}\rho_{\mathrm{o}}=\rho_{\mathrm{t}}(\mathrm{I}-\mathrm{kt} .) \\
\text { 'remp. Coeff. } \mathrm{k} \text {. }\end{array}$} & \multicolumn{2}{|c|}{$\begin{array}{c}\text { Compressibility } \\
\text { per Atmosphete } \\
\text { at } 0^{\circ} \text {. }\end{array}$} & \multicolumn{2}{|c|}{$\begin{array}{l}\text { Surface Tension } \\
\text { at of in isynes. }\end{array}$} \\
\hline & ['08942 & .000 & & & 000016 & 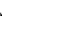 & -783 \\
\hline 'l'rihydrol . . & iss & .000 & & & $000010(?)$ & & $733^{2}$ \\
\hline & $\begin{array}{c}\text { Critical Tem- } \\
\text { perature. }\end{array}$ & $\begin{array}{l}\text { Specific Heat } \\
\text { at } 0^{\circ} .\end{array}$ & $\begin{array}{l}\text { Saten } \\
\text { of } \mathrm{Fu}\end{array}$ & $\begin{array}{l}\text { Heat } \\
\text { ion. }\end{array}$ & $\begin{array}{l}\text { Latent He } \\
\text { Evaporat }\end{array}$ & $\begin{array}{l}\text { at of } \\
\text { ion. }\end{array}$ & $\begin{array}{l}\text { Yiscosity } \\
\text { at } 0^{\circ} \text {. }\end{array}$ \\
\hline Dihydrol. . & $368^{\circ} \mathrm{C}$ & $\cdot 8$ & & & 257 cal. & & 10030 \\
\hline Trihydrol & $53^{\circ} \mathrm{C}$ & $\cdot 6$ & I6 cal & ries. & 250 cal app & rox. & .0381 \\
\hline
\end{tabular}

The method of determining the density of one of the ingredients of water will now be given to serve as an example of Sutherland's manner of procedure. A curve is plotted in which the ordinates are the densities of water and the abscissas the corresponding temperatures. The curve has its maximum ordinate of $4^{\circ}$ and then sinks toward the axis of $X$, appearing to approach a straight line asymptotically. It seems reasonable to take this straight line as giving the

* Sutherland, Phil. Mag. Series 5, Vol. L, p. 460, I900. "The Molecular Constitution of Water," 
density-temperature relations of one of the ingredients of water. Following the line back until it meets the axis of $\mathrm{Y}$, the density at $0^{\circ}$ is read off as 1083 . From considerations based on surface tension it is later shown that this ingredient is dihydrol.

Mendeleeff has calculated an equation giving the density of water as a function of the temperature. Sutherland throws this equation into a form in which the density is the sum of five terms. By regarding water at any temperature as a mixture of water having the composition which it possesses at $4^{\circ}$ and of additional dihydrol, and further by assuming that both of these ingredients expand with heat in a similar and simple manner, he obtains another expression for the density of water at any temperature which also has five terms similar to those of the transformed Mendeléeff formula. From comparison of like terms of the two formulas it follows that the density of dihydrol at $0^{\circ}$ is I.08942, which agrees well with the value I.083 found from the curve. It will not escape notice how much this result rests upon assumptions.

The following table shows the parts by weight of trihydrol in water at different temperatures under pressures of $I$ and 150 atmospheres respectively.

\begin{tabular}{|c|c|c|c|c|c|c|c|c|c|}
\hline$t$ & $0^{\circ}$ & $20^{\circ}$ & $40^{\circ}$ & $60^{\circ}$ & $80^{\circ}$ & $100^{\circ}$ & $120^{\circ}$ & $140^{\circ}$ & $19^{\circ}$ \\
\hline At I atmo. & $\cdot 375$ & $32 \mathrm{I}$ & 284 & $\cdot 255$ & $\cdot 234$ & 217 & $\cdot 203$ & 'Tgr & '165 \\
\hline At $150^{\prime \prime}$. & $35 \mathrm{I}$ & 300 & 264 & .237 & 217 & $\cdot 203$ & & 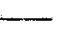 & \\
\hline
\end{tabular}

It is calculated that at 2,300 atmospheres pressure there would be no trihydrol in water at $0^{\circ}$.

By Eötvös and by Ramsay and Shields it has been proved that for all normal liquids the temperature rate of change of a certain function of the surface tension, molecular weight and density of the liquid is the same and remains nearly constant almost up to the critical temperature. At temperatures below $40^{\circ}$ water has this same constant provided the density and molecular weight of trihydrol, and not those of water as ordinarily understood, are taken. From $60^{\circ}$ upward the same constant is approached if the density and molecular weight of dihydrol are used. Therefore up to $40^{\circ}$ the surface layer of water 
consists of trihydrol alone and beyond this dihydrol forms in greater and greater quantity with ascending temperature. The reason why the surface film differs in composition from the body of the water is that in the film tension manifests itself, and, if pressure converts trihydrol into dihydrol, then tension should produce the opposite change. Above $60^{\circ}$, however, the surface tension is so far reduced as to permit some dihydrol to form.

Sutherland says "The solubility of substances in trihydrol may be different from that in water." In connection with this the experiments of Jan von Zawidski * are of interest. He found that foam from aqueous solutions of acetic and of nydrochloric acids containing also some saponin was slightly richer in the acids than the body of the liquid, and that the difference of composition showed itself to a very marked degree in saponin solution by itself.

Sutherland regards the heat of fusion of ice as including the heat required to dissociate some trihydrol into dihydrol. This also holds for the specific heat of water. The latent heat of vaporization likewise includes the heat of dissociation of dihydrol into hydrol. It is calculated that I 89 small calories are needed to change I gram of dihydrol into hydrol, at $100^{\circ}$ and 177 to change 1 gram trihydrol into dihydrol at $0^{\circ}$.

Sutherland suggests these graphic formulæ for trihydro1 and dihydrol in which o has valency of 4 .
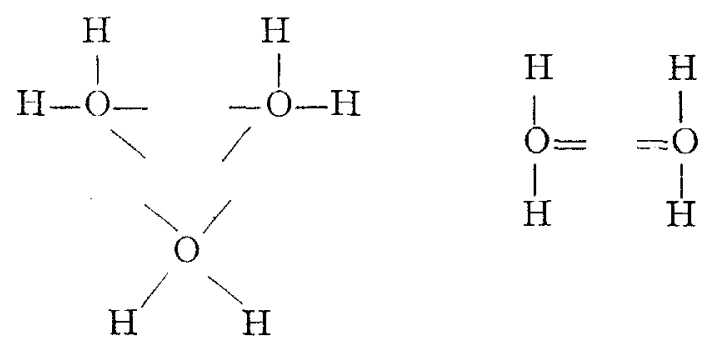

The hexagonal form of ice crystals seems to be the most probable grouping to be expected of molecules in which

* Jan von Zawidski. Zeit. fur phys. Chem., XXXV, p. 77. "Zur Kenntniss der Zusammensetzung der Oberflächenschichten wässeriger Lösungen." 
the equilateral triangle marked out by the three oxygen atoms is the chief feature.

The problem confronting Sutherland was this: Given a substance, whose behavior, especially as a liquid, is anomalous in a number of respects, to determine what must be the respective quantities, rates of change and physical constants of two simple and normal substances, by whose mixture the comportment of water shall be reproduced. Of necessity he often makes appeal to analogy with ordinary substances, for it is one of the conditions of the problem that the solution shall be in terms of such substances. Hypothesis often confronts the reader where he could wish for something firmer, yet the longer he reads the paper the surer he becomes that at last a scientific and quantitative explanation of the comportment of water exists.

G. Tamman * has found that in addition to ordinary ice there are two other varieties, II and III. They differ from the common kind in these respects.

(I) Their melting points are raised by the application of pressure, whereas the opposite is true of ordinary ice.

(2) Their density is greater than that of water. This aczounts for the effect of pressure upon their melting points.

(3) They are formed only under special conditions of temperature and pressure. Common ice is cooled below $22^{\circ} \mathrm{C}$. and the pressure raised to at least 2,400 kilograms per cm. ${ }^{2}$ Now if the temperature is further lowered until it is from $-30^{\circ}$ to $-60^{\circ} \mathrm{C}$. ice III forms; if it is lowered to $-80^{\circ} \mathrm{C}$. ice II forms.

When ordinary ice changes into ice II the following diminutions of volume per gram occur.

$$
\begin{array}{ll}
-73^{\circ} & { }^{\circ} 7 \mathrm{I} \mathrm{cm} .^{3} \\
-55^{\circ} & \cdot 180 \\
-34^{\circ} & \cdot 193
\end{array}
$$

The heat of transformation of common ice into ice II or ice III is positive or negative or zero according to the tem.

* G. Tamman, Drude's Ann., II, p. I. "Ueber die Grenzen des festen Zustandes," IV. 
perature. The lowest temperature at which Tamman observed water and joe to exist together was $-224^{\circ} \mathrm{C}$, the pressure being 2,230 kilograms per cm." He gives the following table of the temperatures at which ice is melted at the accompanying pressures.

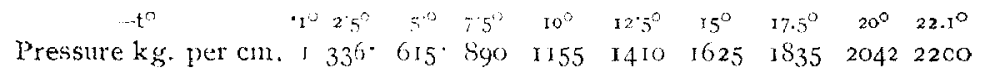

It appears that the lowet the temperature the less is the additional pressure requisite to prodtuce a further lowering of the melting point by 1 .

When we rellect for how long a time air and water have been the objects of scientific investigation it is indeed remarkable that they both still richly repay re-examination.

I take the liberty of quoting here a paragraph in a letter from Mr. Hugo Witt to me. "It seems to me to be a great mistake first to study aqueous solutions and then other solutions. Water is, as I believe to have shown, and as Roentgen, van I,aar and others believe (Professor Arrhenius believes also, he has told me, in the ice molecules) a very complicated substance, and there must in the process of solution in water be great exceptions from the simple rules which exist for other solvents that are not associated. And the chapter in treatises on physical chemistry, "Theorie der Lösungen' should rightly be entitled 'Theorie der Wässerigen Lösungen.'" Not only in the matter of solutions but in other more strictly physical relations it is a misfortune that the role of the typical liquid was assigned to water. 